\title{
Ultrasound versus temporal artery biopsy in patients with Giant cell arteritis: a prospective cohort study
}

\author{
Quan Zou ${ }^{1 *}$ (D), Sumei Ma ${ }^{1}$ and Xinghu Zhou²
}

\section{Abstract}

Background: Diagnosis of giant cell arteritis by temporal artery biopsy is time-con, ing ana isual loss lies in the first week after its diagnosis. The purpose of the study was to test the hypothesis that rasound can reduce the risk of overdiagnosis and overtreatment in giant cell arteritis.

Methods: Data regarding physical/ clinical features examinations, temporar pry examinations, ultrasound findings, and magnetic resonance imaging examinations of 980 suspected pat ts, for giant cell arteritis were included in the study. Decision curve analysis was applied to get a be crial scere for selected diagnostic modalities. Cost analysis was performed for each patient.

Results: Fewer numbers of false positive giant cell arteritis recults were aported under physical/ clinical features examinations following ultrasound detection than physic clin. features examinations following temporal artery biopsy examinations ( 45 vs. 127, $p<0.0001$ ). The working tho detects giant cell arteritis at least one time for physical/ clinical features examinations following ulasound ection and physical/ clinical features examinations following temporal artery biopsy examinations we - 0, $1 \%$ and 0-86\%. No significant difference for true negative results between magnetic resonance imaging and $\mathrm{pl}$ ical and clinical features examinations following ultrasound detection $(p=0.007)$. Physical and clinical féa method than physical/ clinical features fvamina ns following temporal artery biopsy examinations (14,023 \pm 982 $¥$ /patient vs. $18,551 \pm 1231 ¥$ /patient $p<0.0001$ ) and MRI.

Conclusion: Physical and clinical fe res exalminations following ultrasound are recommended for diagnosis of patients with suspected giant cell arte

Keywords: Giant cell arteritis, Ilay resonance imaging, Overdiagnosis, Overtreatment, Temporal artery biopsy, Ultrasound

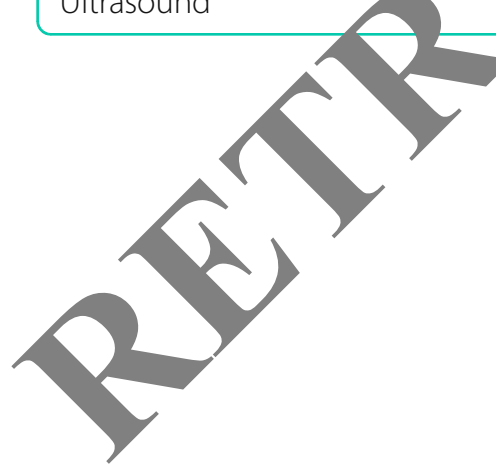

\footnotetext{
* Correspondence: BrigitteFitzpatrickpqi@yahoo.com

${ }^{1}$ Department of Ultrasound, the first hospital of Lanzhou University, Lanzhou 730000, China

Full list of author information is available at the end of the article
}

C The Author(s). 2019 Open Access This article is distributed under the terms of the Creative Commons Attribution 4.0 International License (http://creativecommons.org/licenses/by/4.0/), which permits unrestricted use, distribution, and reproduction in any medium, provided you give appropriate credit to the original author(s) and the source, provide a link to the Creative Commons license, and indicate if changes were made. The Creative Commons Public Domain Dedication waiver (http://creativecommons.org/publicdomain/zero/1.0/) applies to the data made available in this article, unless otherwise stated. 


\section{Background}

Giant cell arteritis or temporal arteritis is vasculitis and has been found in more than 50 years age people [1] leads to aortitis, stroke, blindness [2], or myocardial infarction [3]. Very large populations with giant cell arteritis are found in China [4]. Glucocorticoid treatment after rapid diagnosis is generally recommended in giant cell arteritis [5]. The diagnosis of giant cell arteritis is not straightforward but it is made on temporal artery biopsy and the decision is supported by presenting symptoms [6] but its sensitivity is varied from 39 to $91 \%$, because of drug intake e.g. glucocorticoid took by patients have effect on the results of temporal artery biopsy means, has large numbers of false negatives results can be found [1], which lead to use of a high dose of glucocorticoid as precaution. Moreover, diagnosis by temporal artery biopsy is time-consuming [7] and visual loss lies in the first week after its diagnosis [8]. In short, temporal artery biopsy is considered as 'gold standard' for giant cell arteritis [9] but there are poor associations between the results of temporal artery biopsy and giant cell arteritis especially multi-vessels giant cell arteritis [10]. Besides, temporal artery biopsy, ultrasound [11] and magnetic resonance imaging (MRI) [12] are non-invasive techniques used for diagnosis of giant cell arteritis but MRI has issues of availability and cost [1]. Addition ally, no ionizing radiation involved in ultrasound [13] ${ }^{\mathrm{r}} \mathrm{tr}$ sound has high specificity $(100 \%)$ but very $10 w$ ( 4 ) sensitivity was reported for the diagnosis of $y$ t cell $a_{1}$ teritis [14]. Moreover, glucocorticoid traamen an be started before a formal diagnosis, wh ch leads to veight gain, hypertension, cataract, osteopc osis, and thin skin [1]. Overall, giant cell arteritis has pr oms of overdiagnosis and overtreatment.

The primary aim of the study wa, compare sensitivity, specificity, and $\cos ^{+}$ltras ound with temporal artery biopsy consider $M$ as $\mathcal{H}$ reference standard in patients with suspectea int cell arteritis. The secondary endpoint of study as to test the hypothesis that ultrasound can $r$ ce the risk of overdiagnosis and overtreat ment in gian, cell arteritis.

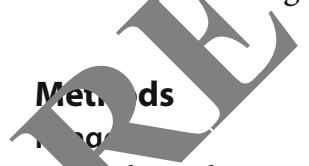

Fon lin, glycerin, hematoxylin, and eosin were purchased from Mark Specialist Pvt. Ltd., Berlin, Germany. Gadolinium (Omniscan) was purchased from GE Healthcare, Salt Lake City, Utah, USA.

\section{Inclusion criteria}

Patients with recent visual impairment, C-reactive protein level less than $5 \mathrm{mg} / \mathrm{dL}$, jaw or tongue claudication, shoulder girdles (pain and stiffness in the shoulder), pain in the hip (pelvic girdles), abnormal liver functions, or temporal artery tenderness referred by rheumatologists, ophthalmologist, and neurologists (all have minimum 3years' experience) to the hospital were included in the study cohort.

\section{Exclusion criteria}

Patients with known giant cell arteritis were c uded from the study. Patients who had to recelve glucoce $1 \mathrm{C}$ oid treatment (any glucocorticoid treatm less han 6months prior to study) for the otber reason were excluded from enrollment.

\section{Physical and clinical featur $\leqslant$ e $\lambda$ inations}

The evidence of thicke g, tend ess, and pulsation of both axillary arteries, sca and tongue necrosis were physically exami by neu, physicians (minimum 3years' experie e, inded regarding clinical examinations, temporal ery Diopsy examinations, ultrasound examinat ns, and $R I$ examinations) of the institute. The evidenc posterior or anterior ischemic optic neuropathy afferent pupillary defect, III/IV/V nerve I. or bru is on either side were examined by ophthalmoly sts (minimum 3-years' experience, blinded rerdi g clinical examinations, temporal artery biopsy ex ninations, ultrasound examinations, and MRI examiations) of the institute. The evidence of stroke and aneurysm were examined by a physician (minimum 3years' experience, blinded regarding clinical examinations, temporal artery biopsy examinations, ultrasound examinations, and MRI examinations) of the institutes. The sample of blood was collected from each patient and send to a laboratory for examinations of erythrocyte sedimentation rate (ESR), C-reactive protein level, plasma viscosity, blood cell counts, and hemoglobin. All pathological examinations had been made by pathologists (minimum 3-years' experience, blinded regarding physical features, temporal artery biopsy examinations, ultrasound examinations, and MRI examinations) of the institute [1]. If age at least 50 years, temporal artery abnormalities, elevated ESR ( $\geq 50 \mathrm{~mm} / \mathrm{h}$ ), the new type of localized head pain, and claudication of jaw or tongue was reported in the patient then it was considered as giant cell arteritis [5].

\section{Temporal artery biopsy examinations}

The one-centimeter temporal artery was collected from patients by surgical procedure and send to the laboratory of the institute. The sample was fixed in formalin, embedded in a paraffin block, and slides were stained with hematoxylin and eosin. The prepared slides were observed under a light microscope (Olympus, Beijing, China) in 100 magnifications (Fig. 1) [11]. Histopathological examinations had performed 


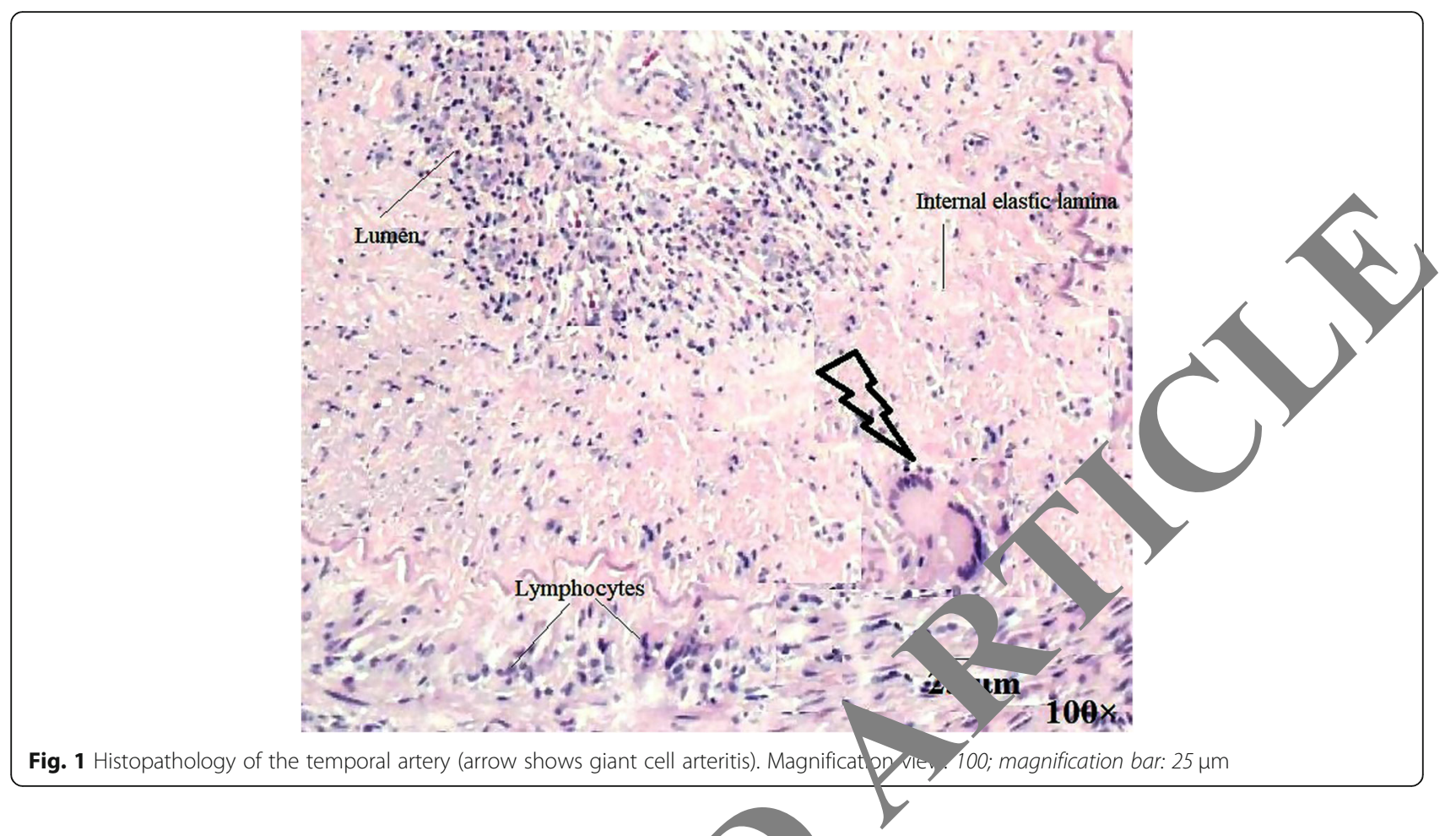

by pathologists (minimum 3-years' experience, (blinded regarding physical features, clinical examinations, ultrass and examinations, and MRI examinations)) of the institut

\section{Ultrasound examinations}

Ultrasound examinations of longitudinar and tra yerse views of both (right and left) tem oral arteries, both (right and left) axillary arteries inclu g brarches, both (right and left) parietal ramus, hoth (ris . id left) proximal frontal ramus, and botl and left) distal frontal ramus had been token $b$ ultrasound equipment (Esaote SpA, Genoa, aly) sing 1 LA 424 linear probe at $13 \mathrm{MHz}$ frequency $\mathrm{SpA}$, Genoa, Italy for B-Mode) and $1 \mathrm{MHz}$ i wency (Esaote SpA, Genoa, Italy for colc D ver). The depth of ultrasound was $1.5 \mathrm{~cm}$ fo tempora teries, axillary arteries including branch p rietal ramus, and proximal frontal ramus. That for tal ontal ramus was $2.5 \mathrm{~cm}$ (Fig. 2) [15]. Uitra und xaminations had performed by ultra'o Is (minimum 3-years' experience, blinded reg ling physical features, clinical examinations, temporal) artery biopsy examinations, and MRI examinations) of the institute.

\section{MRI examinations}

MRI examinations of longitudinal and transverse views of both (right and left) temporal arteries, both (right and left) axillary arteries including branches, both (right and left) parietal ramus, both (right and left) proximal frontal ramu and both (right and left) distal frontal ramus had taken by $3 \mathrm{~T}$ Magnetom Skyra MRI equipment (S.emens, Erlangen, Berlin, Germany) with a 20-channel head coil (Siemens, Erlangen, Berlin, Germany). Diffusionweighted images (a single-shot, spin-echo, and echoplanar), fast saturated T1 W1 (spin-echo sequence), and angiography were recorded before and after administration of $16 \mathrm{~mL}$ of gadolinium. Arterial segments were evaluated in cross-sectional views. Axillary arteries including branches and occipital artery were evaluated for $3 \mathrm{~cm}$ or more in length (Fig. 3) [12]. MR images had performed by radiologists (minimum 3-years' experience, blinded regarding physical features, clinical examinations, temporal artery biopsy examinations, and ultrasound examinations) of the institute.

\section{Image analysis}

Images were uploaded in RadiAnt DICOM Viewer, version 4.9.15 Beta (Mediant, Maciej Frankiewicz, Poznan, Poland).

At least $1.5 \mathrm{~mm}$ swelling of the homogeneous wall was considered as vasculitis (Fig. 4). If artery lumen was 50\% of the original in color Doppler for non-homogeneous walls, was considered as stenotic (Fig. 5) and if the ultrasound was unable to describe the color of nonhomogeneous artery lumen then it was considered as occluded (Fig. 6). A halo (an eccentric or circumferential hypoechoic ring) around the vessel wall (Fig. 7), vasculitis, stenotic, or occluded either of temporal arteries, 


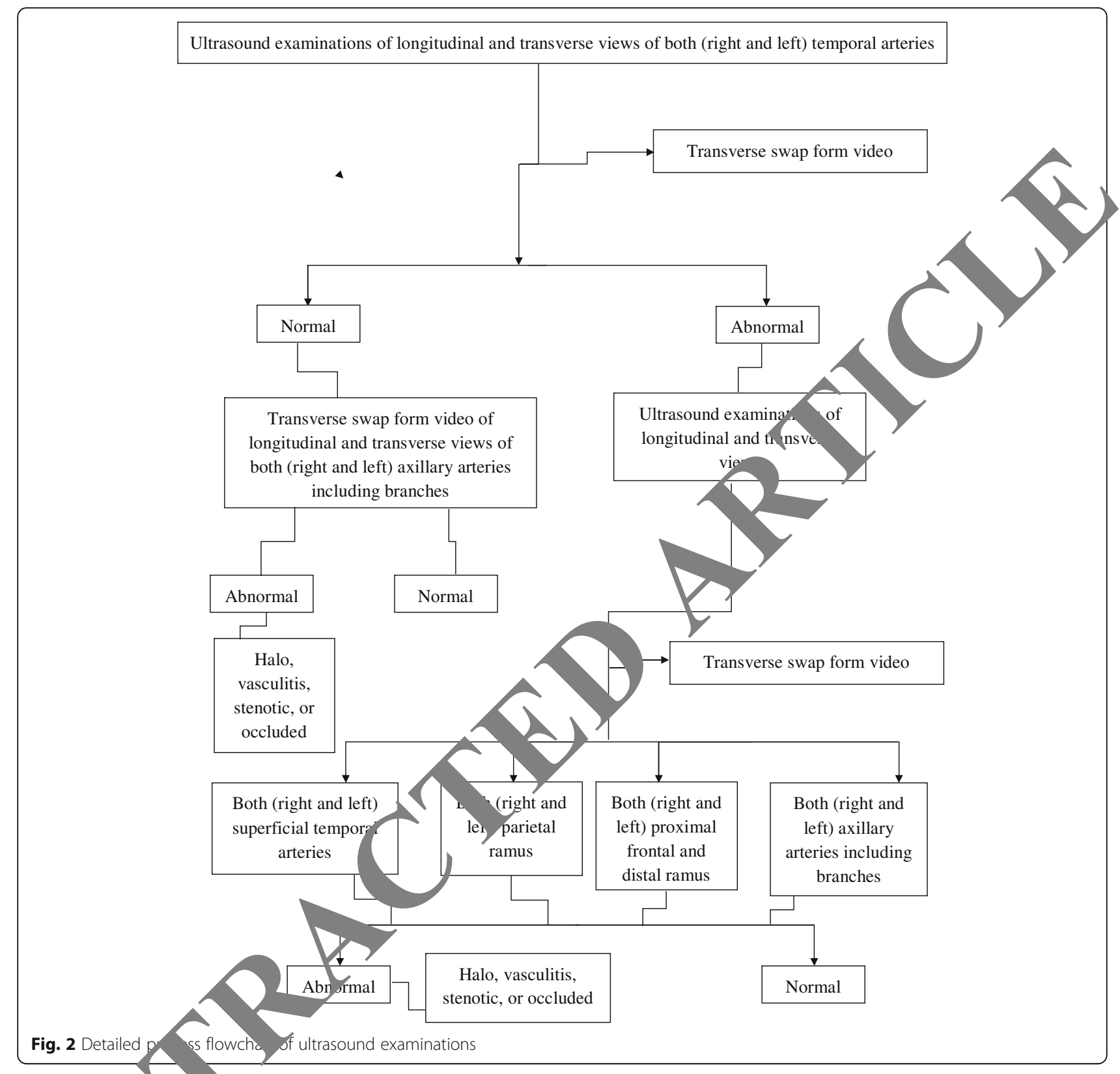

axillary to ies (including branches), parietal ramus, pre nal h tal ramus, or distal frontal ramus was condere as gant cell arteritis [13]. Ultrasound images w anary $z$ ed by ultra-sonographers of the institute with a $\mathrm{m}$ mum of 3 years of experiences in ultrasound image analysis (blinded regarding physical features, clinical examinations, temporal artery biopsy examinations, and MRI examinations).

Mural enhancement and mural thickening were used as evaluation criteria for MR images analysis (Fig. 8). If at least one of ten different MR images either of temporal arteries, axillary arteries (including branches), parietal ramus, proximal frontal ramus, or distal frontal ramus had mural thickening of $0.6 \mathrm{~mm}$ or more and significant mural enhancement was considered as giant cell arteritis [16]. MRI was analyzed by radiologists of the institute with a minimum of 3 years of experiences in MR image analysis (blinded regarding physical features, clinical examinations, temporal artery biopsy examinations, and ultrasound examinations).

\section{Beneficial score analysis}

Decision curve analysis was applied to get a beneficial score for selected diagnostic modalities as per Eq. 1 and 2 [17]: 


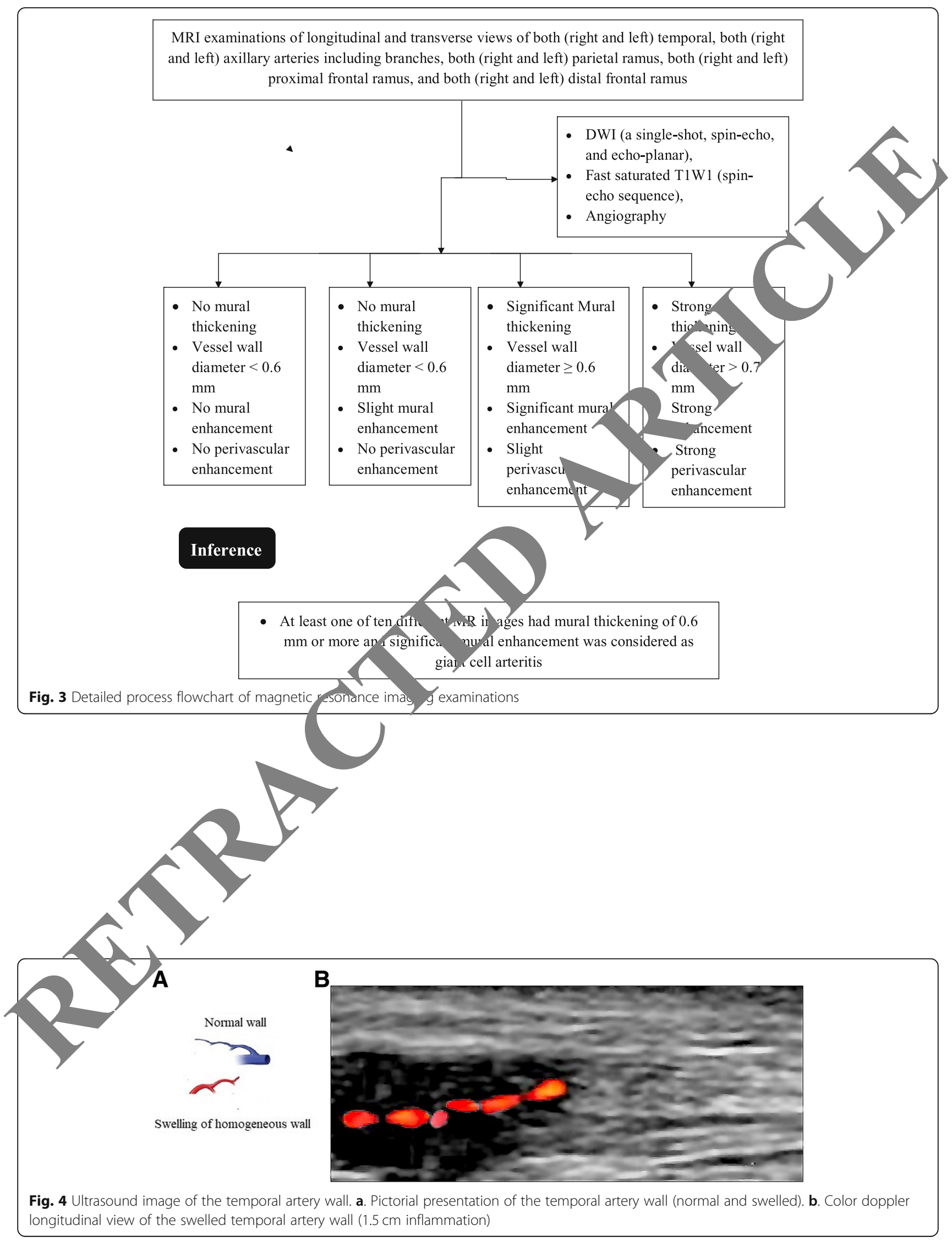


Beneficial score $=\frac{\text { True positive giant cell arteritis detected }}{\text { Numbers of patients enrolled }}-\left(\frac{\text { False positive giant cell arteritis detected }}{\text { Numbers of patients enrolled }} \times\right.$ Risk of overdiagnosis and overtreatment $)$

Risk of overdiagnosis and overteratment $=\frac{\text { Level of confidence above which patients were put on glucocorticoid as a precaution }}{1-\text { Level of confidence above which patients were put on glucocorticoid as a precartion }}$

\section{Cost analysis}

Physician charges for physical and clinical features examinations, to perform biopsies following histopathology, ultrasound findings, and MRI examinations [1] were collected from patients' record of the institute(s) and pharmacy.

\section{Statistical analysis}

InStat, version Window, GraphPad Software, San Diego, CA, USA was used for statistical analysis. The interobserver agreement was derived by Cohen $k$ test (value of $k \geq 0.80$ considered as outstanding agreement and a value of $0.8>k \geq 0.60$ was considered as good agreement) according to Landis and Koch [16]. Constant data were analyzed by the Chi-square test of Independence [12]. Continuous variables were analyzed by one-yay analysis of variance (ANOVA) or Wilcoxon's signe raik test [11]. The results were considered significant at \% of confidence level.

\section{Results}

\section{Characteristics of study participants}

During 15 March 2016 to 31 Decem 201\%, a total of 1000 patients were referred the First Hospital of

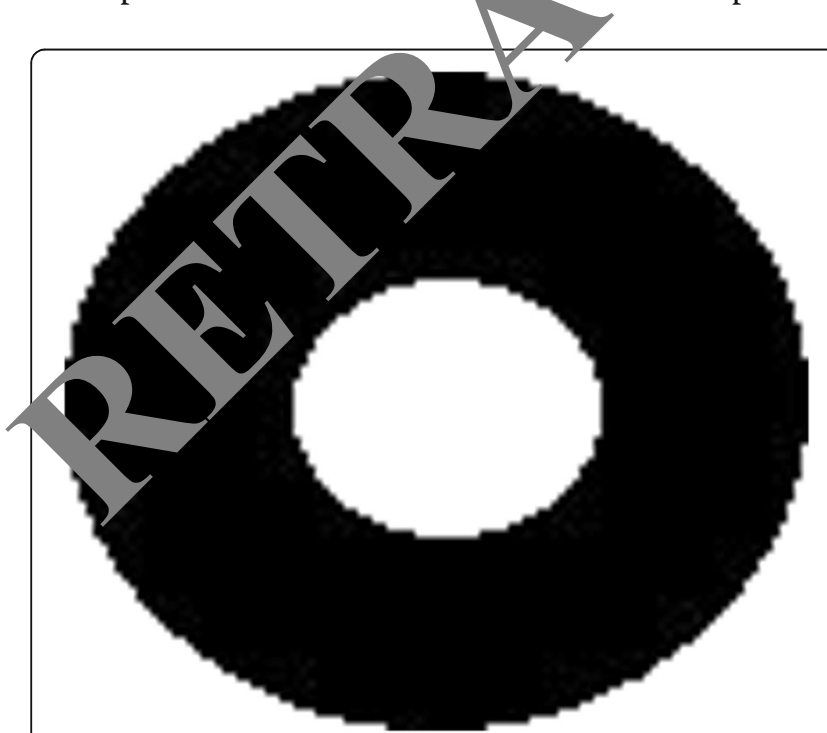

Fig. 5 Pictorial presentation of stenotic (artery lumen was 50\% of the original)
Lanzhou University, China by rhe matologis ophthalmologist, and neurologists as a suspect d disease of giant cell arteritis. Among $t^{1} \mathrm{~m}$, atie ts had already diagnosed with giant cell iter and 15 patients had received glucocorticoid atment. Kerefore, they were excluded from the anllys. Fig. 9).

Data of $980 \mathrm{pa}^{\text {t }}$ s were cluded in the study. Mean age of enrolle pat its were $61.12 \pm 6.56$ years. $48 \%$ of patients were fe tes and $52 \%$ of patients were males. The othe demogr, hic and clinical characteristics of enrolled paty are reported in Table 1. Patients had one or mure symptoms at the time of enrollment. refore, consultants had diagnosed as suspected giant cell eritis.

\section{Interobserver agreement}

A total of seven physicians, five ultra-sonographer, and six radiologists were involved in the interpretations of physical and clinical features, image analysis of ultrasound and MRI respectively. Interobserver agreement for the physical and clinical features interpretations was outstanding $(\mathrm{k}=0.83)$, for image analysis of ultrasound examinations was good $(\mathrm{k}=0.62)$, and for image analysis

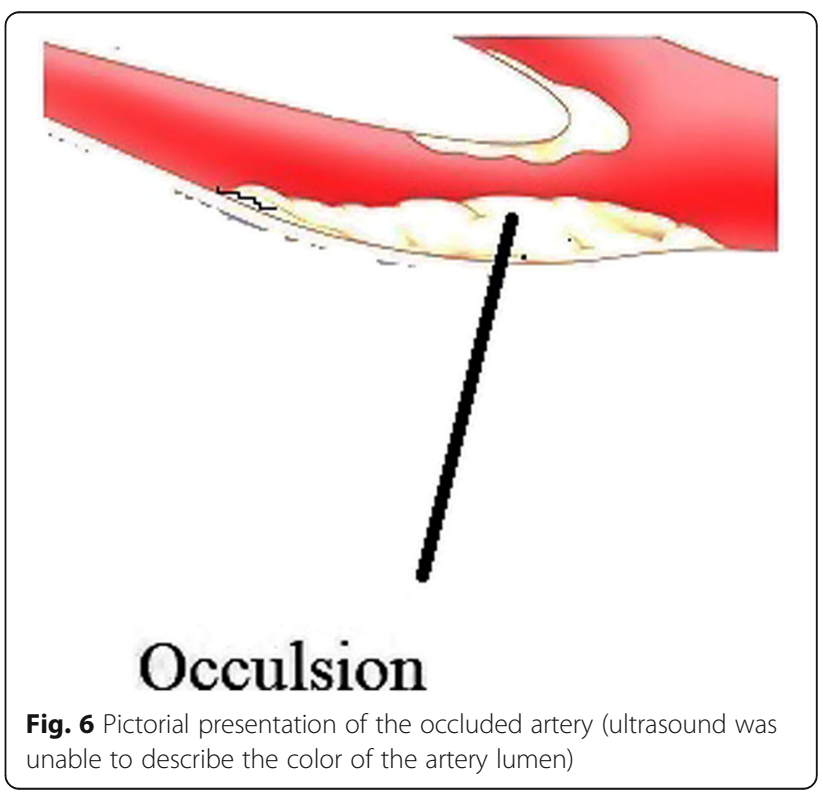




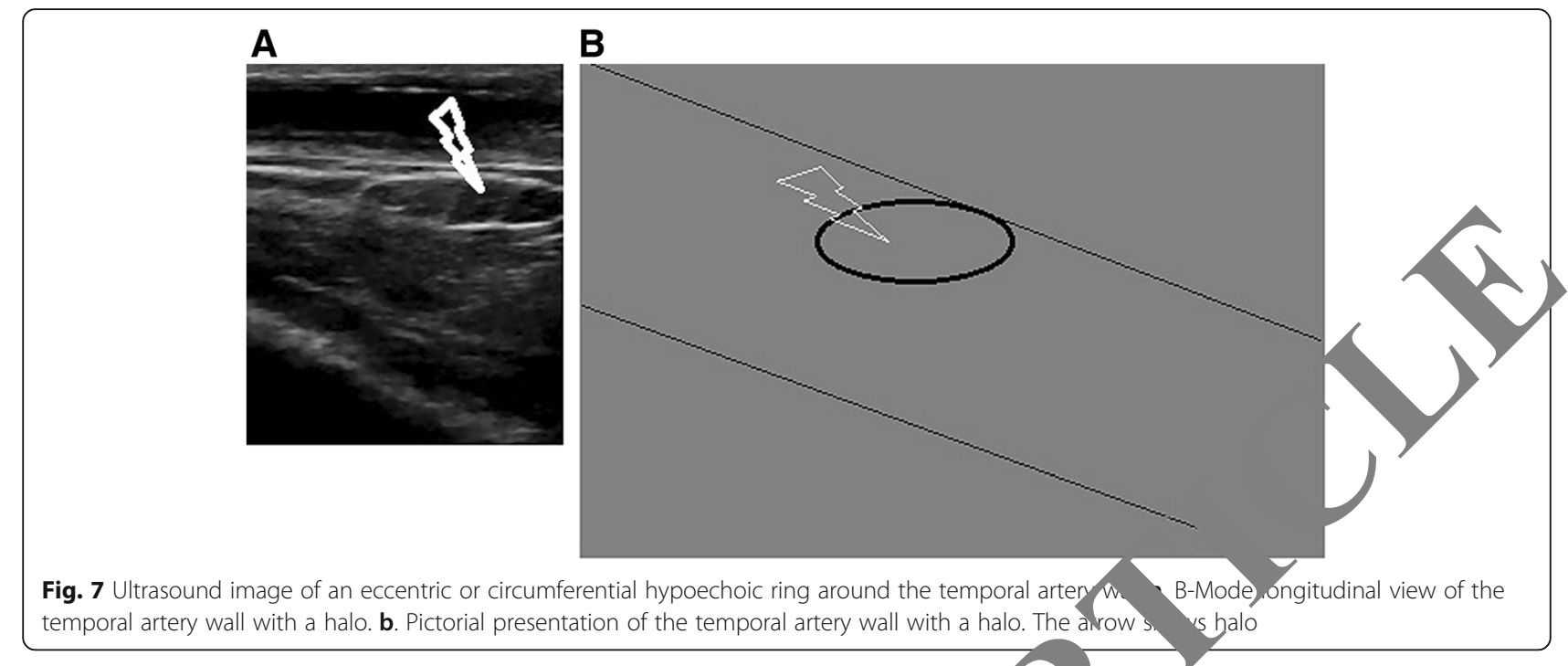

of MRI examinations was good $(\mathrm{k}=0.67)$ respectively (Table 2).

\section{Diagnostic parameters}

More numbers of true positive giant cell arteritis cases (650 vs. 643) and true negative giant cell arteritis cases (100 vs. $50, p<0.0001)$ were reported in case of physical and clinical features examinations following ultras and detection than physical and clinical features ex in tions following temporal artery biopsy exarmat Also, less numbers of false positive giant 1 arterit cases ( 45 vs. $127, p<0.0001)$ and false negative arteritis cases ( 15 vs. $35, p=0.007$ ) we re reported 1,1 case of physical ana $\mathrm{l}_{\mathrm{i}}$ - catures examinations following ultrasound detecu than physical and clinical features examinati following temporal artery biopsy examinations. Sensiti 11 y was in the order of MRI examinations $>$ physical and clinical features examinations following ten ral artery biopsy examinations $>$ physical and clinical atures examinations following ultrasound detecbut accuracy were in the order of MRI examinations > physical and clinical features examinations following ultrasound detection $>$ physical and clinical features examinations following temporal artery biopsy examinations. There was no significant difference for true negative results between MRI and physical and

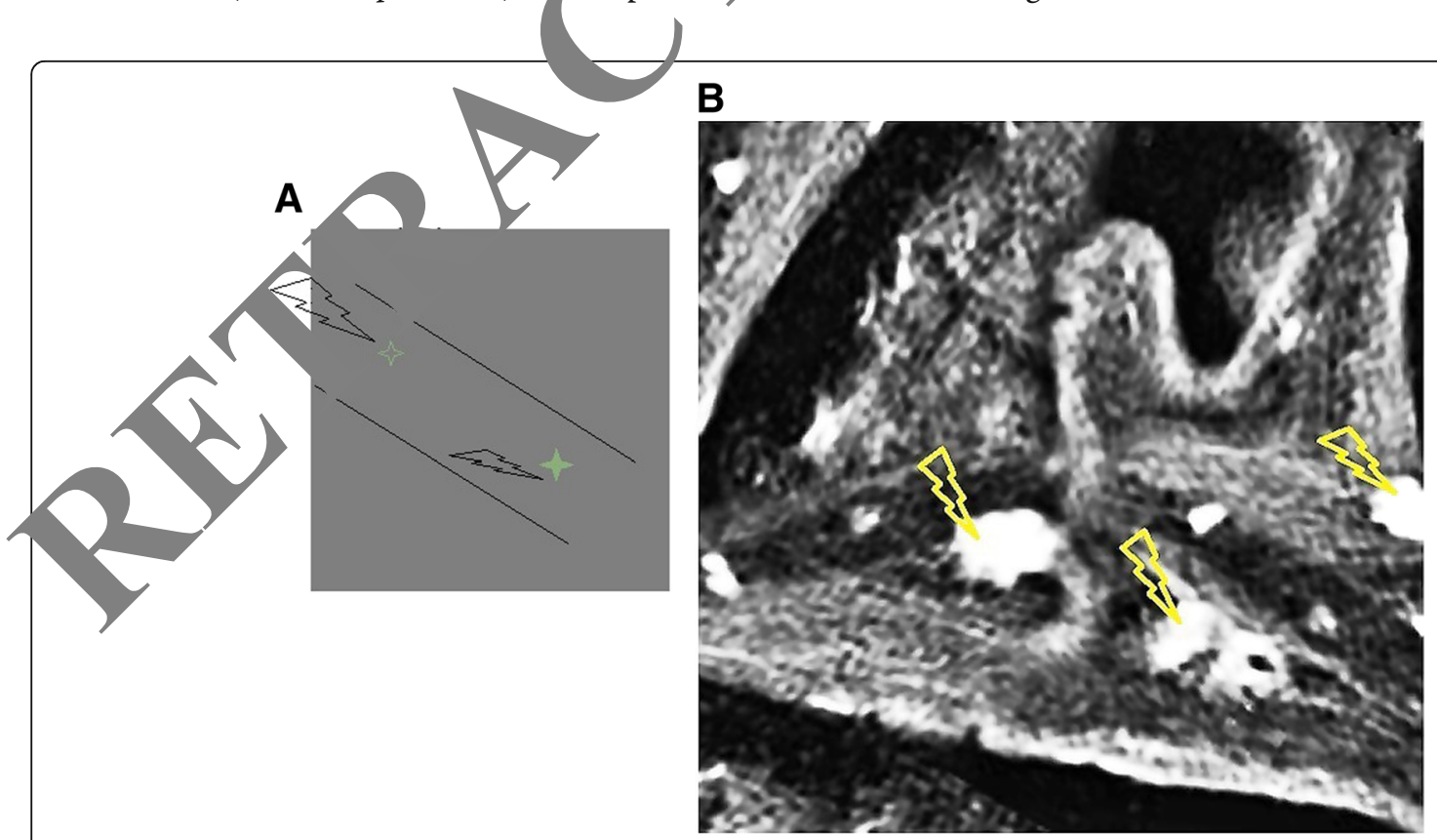

Fig. 8 Diagnosis of giant cell arteritis by magnetic resonance image a. Pictorial presentation of mural thickening. b. Magnetic resonance image of a longitudinal view of the temporal artery. The arrow shows mural thickening 


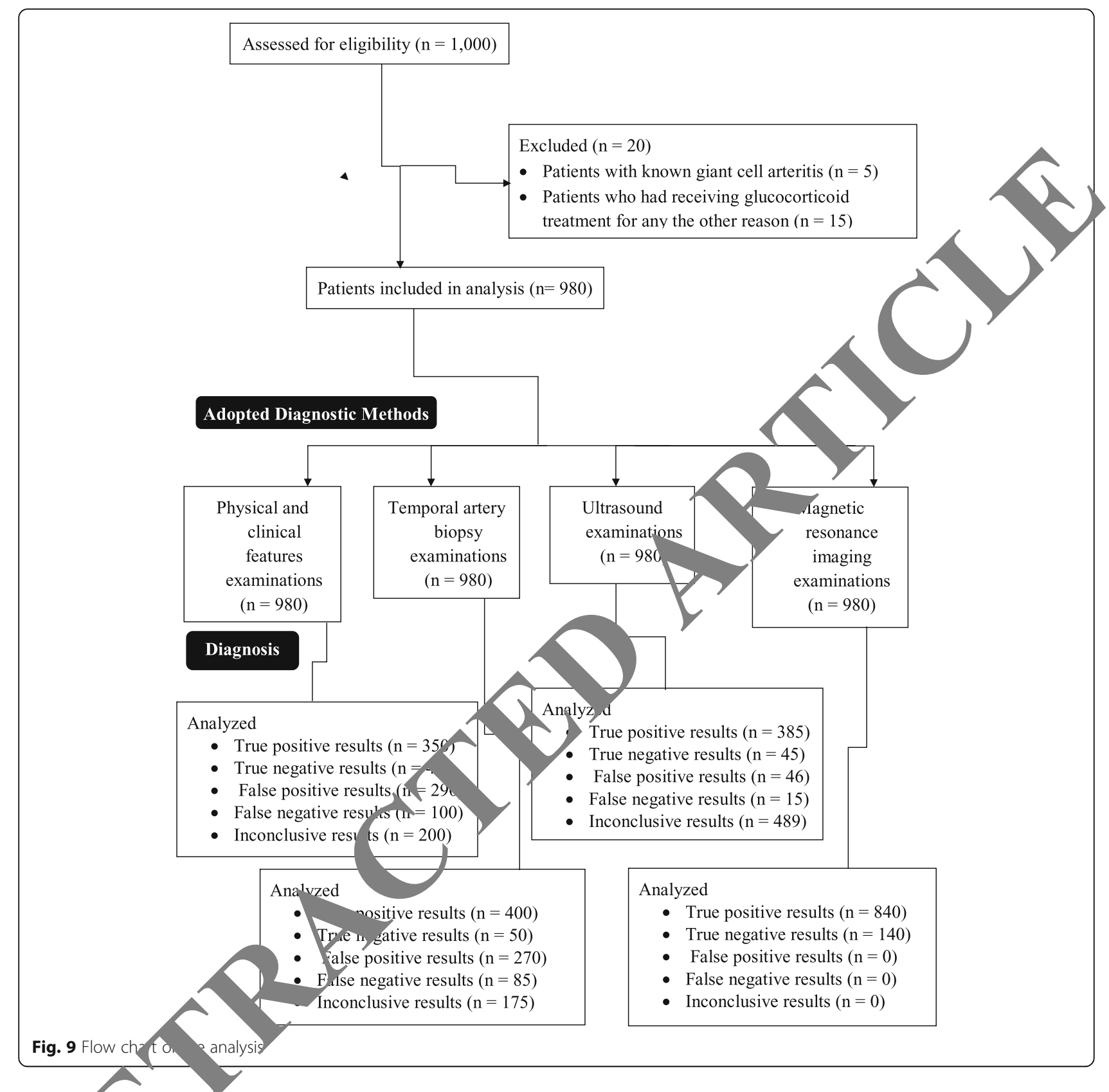

clinicar following ultrasound detectiv (14 S. $100, p=0.007$, Table 3).

\section{ISK u. Overdiagnosis and overtreatment}

The rking area that detects giant cell arteritis at least one time for physical/ clinical features examinations following ultrasound detection and physical/ clinical features examinations following temporal artery biopsy examinations were 0-91\% (high- and medium-risk giant cell arteritis patients) and 0-86\% (high-risk giant cell arteritis patients) respectively. Above 91\% (for low-risk giant cell arteritis patients) for ultrasound detection and above $86 \%$ (for low-and medium-risk giant cell arteritis patients) for temporal artery biopsy had the risk of overdiagnosis and overtreatment respectively (Fig. 10).

\section{Cost}

Physical and clinical features examinations following ultrasound detection were less expensive method than physical and clinical features examinations following temporal artery biopsy examinations $(14,023 \pm 982 ¥ /$ patient vs. $18,551 \pm 1231 ¥ /$ patient, $p<0.0001$, Fig. 11$)$.

\section{Discussion}

The prospective cohort study concluded that physical/ clinical features examinations following ultrasound 
Table 1 The demographic, social, and clinical characteristics of enrolled patients

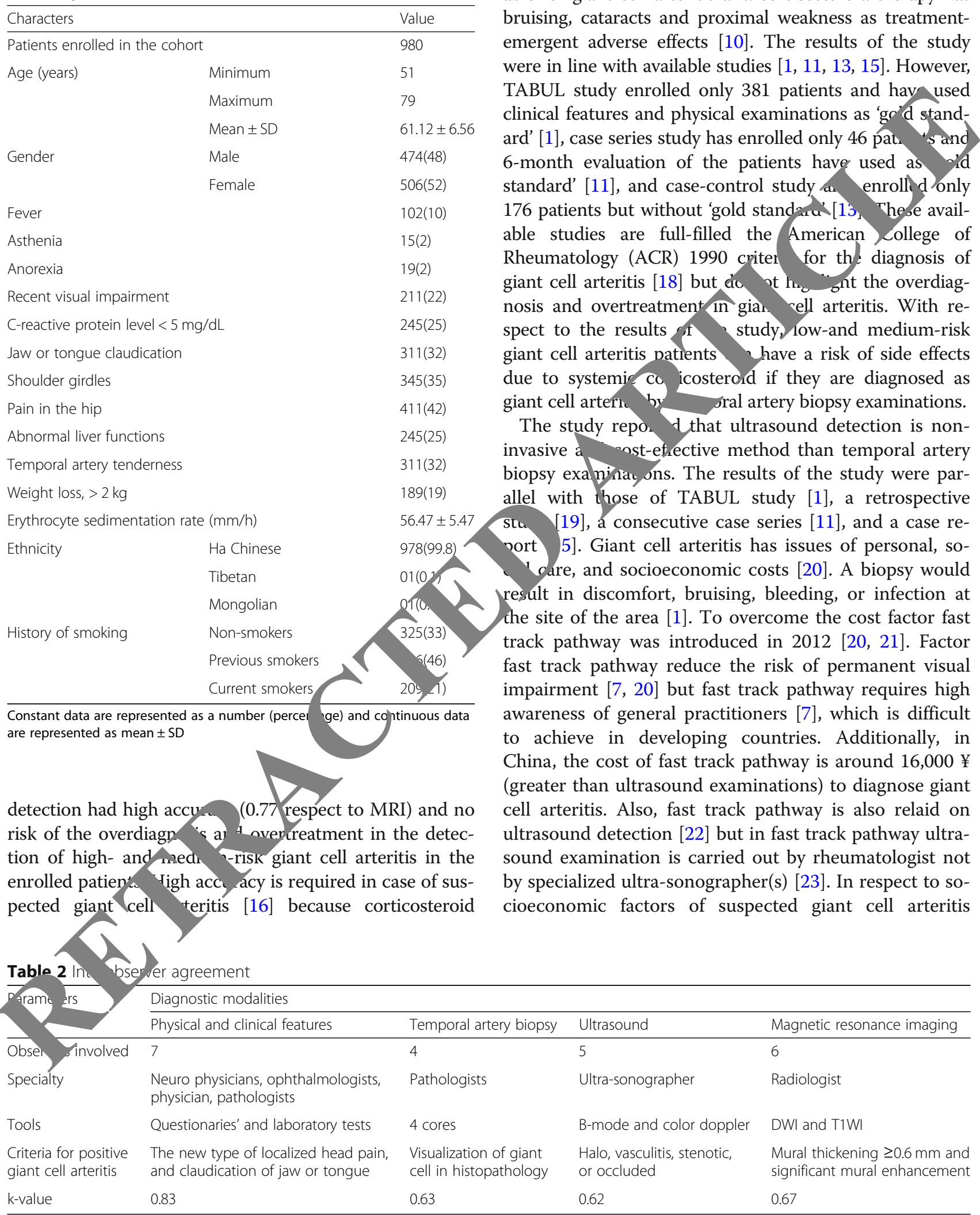

$\mathrm{k} \geq 0.80$ : outstanding agreement, $0.8>\mathrm{k} \geq 0.60$ : good agreement

All observers had minimum 3-years of experience treatment is the only effective treatment currently available for giant cell arteritis and corticosteroid therapy has bruising, cataracts and proximal weakness as treatmentemergent adverse effects [10]. The results of the study 13, 15]. However patients and hav used astand6-month evaluation of the patients have used as $/ d$ standard' [11], and case-control study a enroll d only 176 patients but without 'gold standrac' [13, Theoe available studies are full-filled the American college of Rheumatology (ACR) 1990 criter for the diagnosis of giant cell arteritis [18] but do ot $\mathrm{h}$. nosis and overtreatment in gia cell arteritis. With respect to the results i study, low-and medium-risk giant cell arteritis patients have a risk of side effects due to systemi Co icosteroid if they are diagnosed as iant cell arteri by oral artery biopsy examinations.

The study repo $d$ that ultrasound detection is noninvasive a ost-et.ective method than temporal artery biopsy exalniau, ons. The results of the study were par[19], a consecutive case series [11], and a case re5]. Giant cell arteritis has issues of personal, soresult in discomfort, bruising, bleeding, or infection at the site of the area [1]. To overcome the cost factor fast track pathway was introduced in 2012 [20, 21]. Factor fast track pathway reduce the risk of permanent visual impairment $[7,20]$ but fast track pathway requires high awareness of general practitioners [7], which is difficult to achieve in developing countries. Additionally, in China, the cost of fast track pathway is around 16,000 $¥$ (greater than ultrasound examinations) to diagnose giant cell arteritis. Also, fast track pathway is also relaid on ultrasound detection [22] but in fast track pathway ultrasound examination is carried out by rheumatologist not by specialized ultra-sonographer(s) [23]. In respect to socioeconomic factors of suspected giant cell arteritis 
Table 3 Diagnostic parameters of adopted modalities

\begin{tabular}{|c|c|c|c|c|c|c|c|c|c|c|c|}
\hline \multirow{3}{*}{$\begin{array}{l}\text { Parameters of giant } \\
\text { cell arteritis }\end{array}$} & \multicolumn{11}{|c|}{ Diagnostic modalities examinations } \\
\hline & \multirow[t]{2}{*}{$\overline{M R I}$} & \multicolumn{2}{|c|}{ PC } & \multicolumn{2}{|l|}{$\mathrm{TAB}$} & \multicolumn{2}{|l|}{$P C+T A B$} & \multicolumn{2}{|l|}{ Us } & \multicolumn{2}{|c|}{$\mathrm{PC}+\mathrm{Us}$} \\
\hline & & Value & ${ }^{*} p$ & Value & ${ }^{*} p$ & Value & ${ }^{*} p$ & Value & ${ }^{*} p$ & Value & * $p$ \\
\hline Patients enrolled & 980 & 980 & & 980 & & 980 & & 980 & & 980 & \\
\hline True positive & $840(86)$ & $350(36)$ & $<0.0001$ & $400(41)$ & $<0.0001$ & $643(65)$ & $<0.0001$ & $385(39)$ & $<0.0001$ & & 0001 \\
\hline True negative & 140(14) & $40(4)$ & $<0.0001$ & $50(5)$ & $<0.0001$ & $50(5)$ & $<0.0001$ & $45(5)$ & $<0.0001$ & & \\
\hline False positive & $0(0)$ & $290(30)$ & $<0.0001$ & $270(28)$ & $<0.0001$ & $127(13)$ & $<0.0001$ & $46(5)$ & $<0.0001$ & & \\
\hline False negative & $0(0)$ & $100(10)$ & $<0.0001$ & $85(9)$ & $<0.0001$ & $35(4)$ & $<0.0001$ & $15(2)$ & 0.0003 & & \\
\hline Inconclusive & $0(0)$ & $200(20)$ & $<0.0001$ & $175(18)$ & $<0.0001$ & $125(13)$ & $<0.0001$ & $489(50)$ & & & 0001 \\
\hline Sensitivity & 1 & 0.8 & $<0.0001$ & 0.82 & $<0.0001$ & 0.87 & $<0.0001$ & 0.5 & & & $<0.0001$ \\
\hline Accuracy & 1 & 0.4 & $<0.0001$ & 0.46 & $<0.0001$ & 0.71 & $<0.0001$ & 0.44 & & & $<0.0001$ \\
\hline
\end{tabular}

MRI Magnetic resonance imaging

$P C$ Physical and clinical features examinations

TAB Temporal artery biopsy examinations results

Us Ultrasound examinations results

Continuous variables are represented as mean and constant variables are represented as number (percentar

Constant data were analyzed by the Chi-square test of Independence

The results were considered significant if $p<0.01$

${ }^{*} p$-value comparison with respect to MRI examinations

patients, conventional ultrasound detection is a suitable diagnostic modality for the detection of giant cell arteritis in Chinese patients.

Large numbers of false negative giant cell arteritis patients were reported by temporal artery biopsy examinations than ultrasound examinations ( 85 vs. $15, p<00) \mathrm{v}$ . The results of the study were parallel with chos if TABUL study [1] and prospective multicen $a$ trial [16, The possible justification for the same was there would be a patchy inflammation in the artery wal, samples of biopsy were taken from the area where no inflammation [11], or incidence of the $1 \mathrm{cel} /$ arteritis in the patients has seasonal var in (an environmental etiology) [ $0 / 24,25]$. All in all, the diagnosis of giant cell arteritis is clinicians' challenge.

study reported that physical and clinical features xam lations following ultrasound detection had min1 sensitivity. The results of the study were in line win TABUL study [1] but not in line with a consecutive case series [11]. The possible reason for that was ultrasonographers had difficulties in capturing abnormalities in ultrasound images. Therefore, training is required for ultra-sonographers before scanning the patients. Also, technical standardization of ultrasound equipment, image acquisition, and probe settings are required. Additionally, MRI would be preferred diagnostic

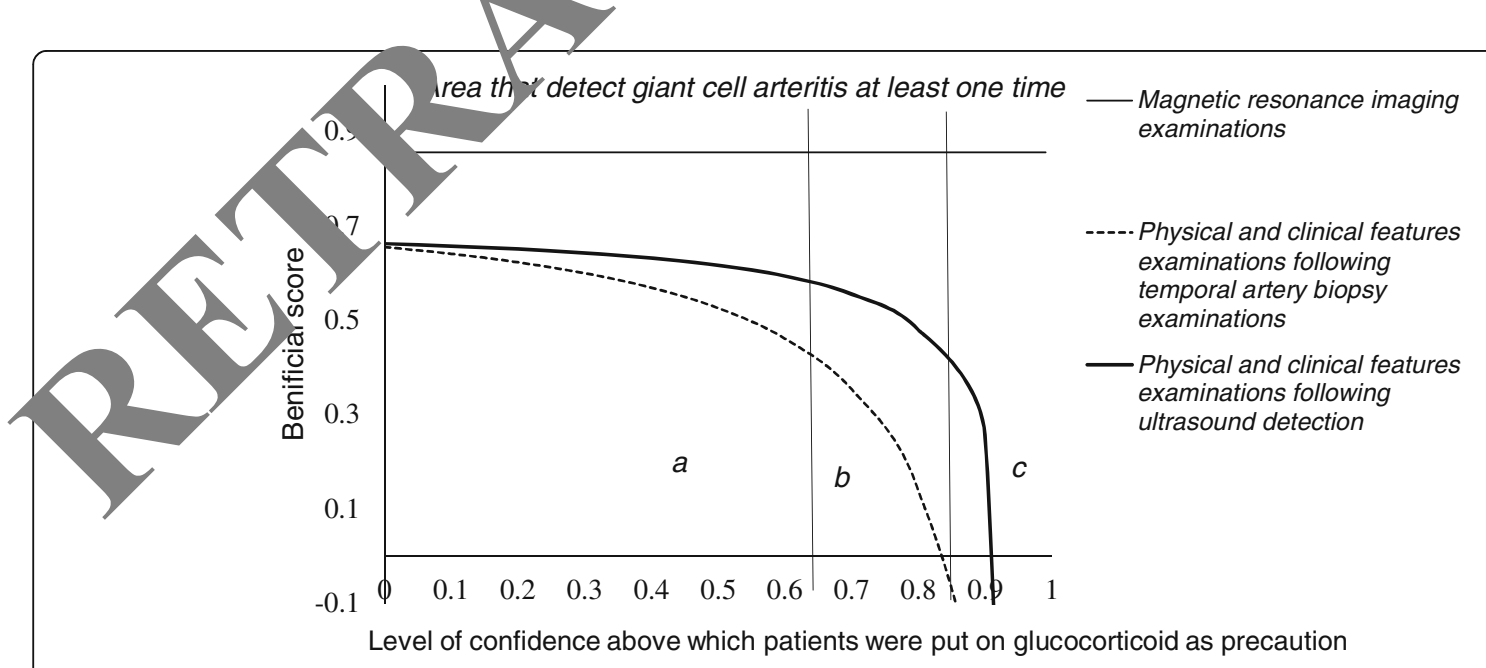

Fig. 10 Decision curve analysis. a: an area that detects high-risk giant cell arteritis at least one time, b: an area that detects medium-risk giant cell arteritis at least one time, c: an area that detects low-risk giant cell arteritis at least one time. Ultrasound images were analyzed by ultra-sonographers, magnetic resonance images were analyzed by radiologists, the physical and clinical features interpretations were performed by physicians, and the biopsies results were interpreted by pathologists (all evaluators had minimum 3 years of experiences) 


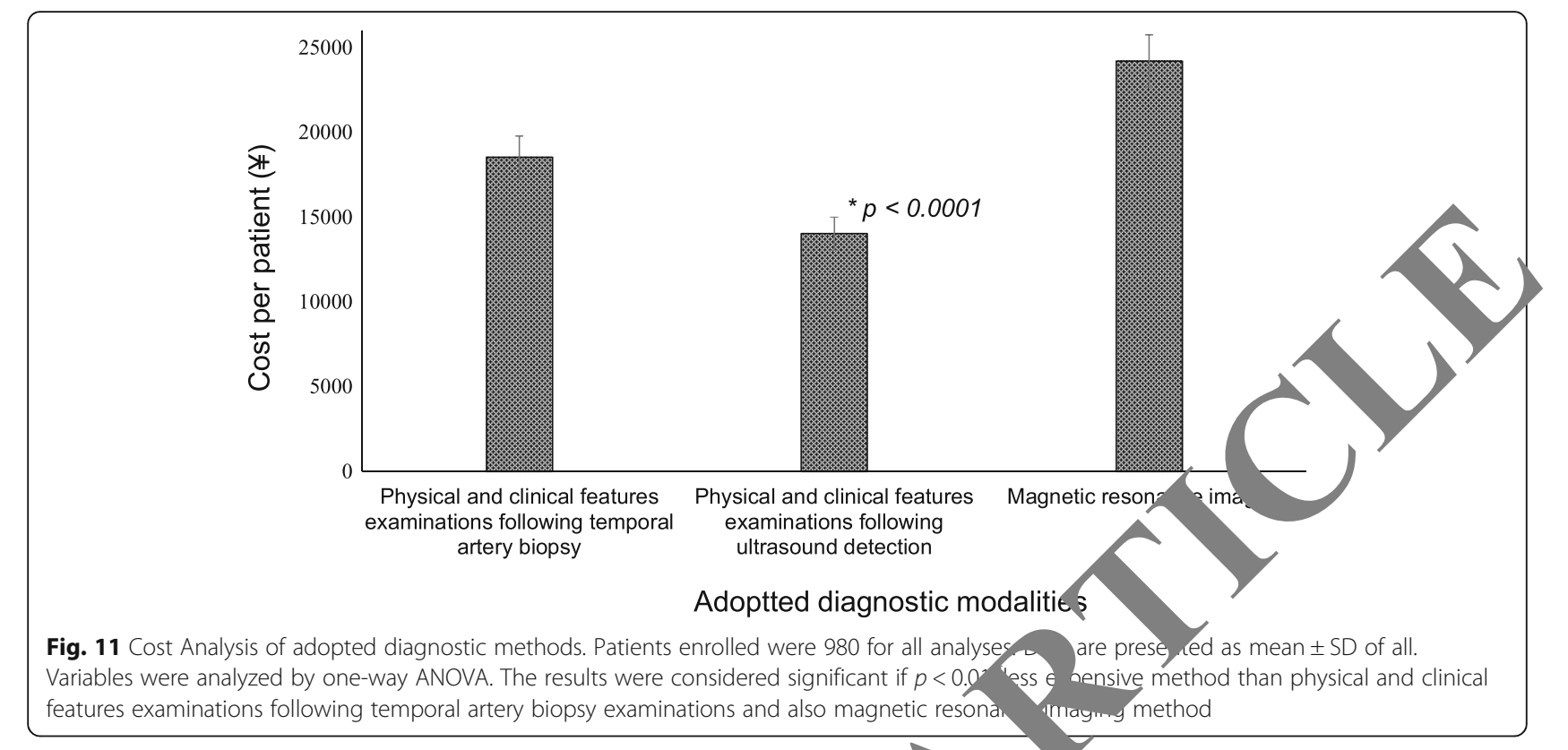

modality in patients, whose diagnosis remains disorganized even after ultrasound examination.

With reference to MRI, physical and clinical features examinations following ultrasound detection had fewer sensitivity and accuracy ( $p<0.0001$ for both) but no significant difference for true negative results $(p, 00)$ ) and cost of diagnosis was also low $(14,023 \pm<02$ patient vs. 24,221 $\pm 1545 ¥$ /per patients, $p<0$ १1). Mly has issues of availability [1]. Additionally in phy $\mathrm{ql}$ and clinical features examinations followng ultrasou, $1 \mathrm{~d}$ do not involve ionizing radiation [13]. IRI has $凤$ low field of view and the contrast enhanceme of wols of arteries would also be due to ath cclerotic plaques [12]. However, ultrasound can successty discrimination of giant cell arteritis an thero clerotic plaques [26]. Moreover, for the ci of ox illis, the thin-walled intradural arteries do sot sh any mural enhancement and/ or mural thig ing uns $\mathrm{MRI}[15,27]$. The MRI protocol is not sp fically adjusted to depict mural inflammation of the aperficial cranial arteries and to visualiz $e$ intrdural arteries [12]. MRI has no ability to 1 rim te polyarteritis nodosa, systemic antineutrohilic cytoplasmatic antibody-positive vasculitis, and ano. Immmmatory disease from giant cell arteritis [16]. How cr, Ultrasound has advantages of safety, availability, tolerability, and its high resolution of $0.1 \mathrm{~mm}$ [23]. Ultrasound of temporal and extracranial arteries also correlates well with MRI [13, 19]. Therefore, physical characters and clinical examinations following ultrasound finding is a suitable modality for the diagnosis of giant cell arteritis.

Although the study was the large sample prospective study, there are several limitations of the study have reported, for exy mples, lack of follow-up data regarding treatment. More numbers of inconclusive results were $\mathrm{re}_{\mathrm{P}}$ ed for physical and clinical features examinations follow ng ultrasound detection than physical and clinical tues examinations following temporal artery biopsy examinations ( 170 vs. $125, p=0.005)$. There are no predefined limits of ultrasound available for the diagnosis of giant cell arteritis in PR China by the ministry of the health department. Lower systemic inflammatory response [4], gender [3], age [10], and the history of smoking [4] have effects on prevalence of giant cell arteritis but the study did not evaluate such independent parameters in the analysis.

\section{Conclusion}

Temporal artery biopsy is a useful technique for the detection of giant cell arteritis but it was a costly and expensive method. Also, it had the chances of overdiagnosis and overtreatment for low-and medium-risk giant cell arteritis. Physical and clinical features examinations following ultrasound detection are non-invasive, economical diagnostic modality, had high specificity, and no chances of overdiagnosis and overtreatment for high and mediumrisk giant cell arteritis. The study recommended an ultrasound technique for diagnosis of patients with suspected giant cell arteritis.

\section{Abbreviations}

ANOVA: Analysis of variance; ESR: Erythrocyte sedimentation rate; MRI: Magnetic resonance imaging; STROBE: The strengthening the reporting of observational studies in epidemiology

\section{Acknowledgments}

Authors are thankful to all medical and non-medical staff of the first hospital of Lanzhou University, Lanzhou, China. 


\section{Authors' contributions}

All authors have reviewed and approved the submitted manuscript for publication. SM was the project administrator and contributed to the data curation, design, and literature review of the study. XZ contributed to the conceptualization, software, literature review, and design of the study. QZ contributed to the formal analysis and literature review of the study, draft, review, and edited the manuscript for intellectual content. The author agrees to be accountable for all aspects of work ensuring integrity and accuracy.

\section{Funding}

None.

\section{Availability of data and materials}

The datasets used and analyzed during the current study available from the corresponding author on reasonable request.

\section{Ethics approval and consent to participate}

The protocol (FLU/CL/6/2017 dated 3 March 2016) of the study had been approved by the first hospital of Lanzhou University review board. The study had adhered to the law of China, the strengthening the reporting of observational studies in epidemiology (STROBE) statement, and the 2008 Helsinki Declaration. All enrolled patients had been signed an informed consent form regarding examinations, biopsies, pathology, and to have an additional procedure for research purpose only.

\section{Consent for publication}

All enrolled patients had been signed an informed consent form regarding publication of the study in all formats hard and electronics including personal data and images irrespective of time and language.

\section{Competing interests}

The authors declare that they have no competing interests.

\section{Author details}

'Department of Ultrasound, the first hospital of Lanzhou University, La 730000, China. ${ }^{2}$ Department of Cardiology, the first hospital of anzhou University, Lanzhou 730000, China.

Received: 25 January 2019 Accepted: 24 May 2019 Published online: 06 June 2019

\section{References}

1. Luqmani R, Lee E, Singh S, Gillett M, So - midt WA, Braunurn M, Dasgupta B, Diamantopoulos AP, Forrester-Barker W, W M Masters S, McDonald B, McNally E, Pease C, Piper J, Salmon J, Wail 00 hy Wolfe K, Hutchings A. The role of ultrasound compared psy of emporal arteries in the diagnosis and treatment of giant $c$ arteri $\angle$ TABUL a diagnostic accuracy and costeffectiveness study. Health s. 2016;20:1-238.

2. Patil P, Karia N, Jain S, Dasgup Giant cell arteritis: a review. Eye Brain. 2013;5:23-33.

3. Ing EB, Lahaie una ven A, Ing R, Chen JJ, Arora N, Torun N, Jakpor OA, Fraser JA adel FJ, Su An AN, Liu X, Lam CT, Patel V, Weis E, Jordan D, Gilber S, Prgnoux C, Ten Hove M. Multivariable prediction model for suspe a ce certeritis: development and validation. Clin Ophthalmol. 2017:11:2-42.

Ma S, eng W, Tian X, Zeng X. A retrospective study of Chinese (Ge) clinical features and factors with severe ischemic manifestations. Medicine. 2016;95. https:/ soclat 10.1097/MD.0000000000003213.

5. Da. gupta B, Borg FA, Hassan N, Alexander L, Barraclough K, Bourke B, Fulcher J, Hollywood J, Hutchings A, James P, Kyle V, Nott J, Power M, Samanta A. BSR and BHPR standards, guidelines and audit working group. BSR and BHPR guidelines for the management of giant cell arteritis. Rheumatology. 2010;49:1594-7.

6. Nesher $\mathrm{G}$. The diagnosis and classification of giant cell arteritis. J Autoimmun. 2014;48-49:73-5.

7. Diamantopoulos AP, Haugeberg G, Lindland A, Myklebust G. The fast-track ultrasound clinic for early diagnosis of giant cell arteritis significantly reduces permanent visual impairment: towards a more effective strategy to improve clinical outcome in giant cell arteritis? Rheumatology. 2016;55:66-70.
8. Danesh-Meyer H, Savino PJ, Gamble GG. Poor prognosis of visual outcome after visual loss from giant cell arteritis. Ophthalmology. 2005;1 12:1098-103.

9. Banerjee PJ, Petrou P, Plant GT. Diagnostic and treatment challenges in giant cell arteritis. Lancet. 2014;383:2210.

10. Dunstan E, Lester SL, Rischmueller M, Dodd T, Black R, Ahern M, Cleland LG, Roberts-Thomson P, Hill CL. Epidemiology of biopsy-proven giant cell arteritis in South Australia. Intern Med J. 2014:44:32-9.

11. Diamantopoulos AP, Haugeberg G, Hetland H, Soldal DM, Bie R, M, m, bust G. Diagnostic value of color Doppler ultrasonography of temp al anteries and large vessels in giant cell arteritis: a consecutive case serie Care Res. 2014;66:113-9.

12. Siemonsen S, Brekenfeld C, Holst B, Kaufmann-Buehle (AK, Fiehler J, D, A. 3T MRI reveals extra- and intracranial involvement in cell arte itis. Am J Neuroradiol. 2015;36:91-7.

13. Schmidt WA, Seifert A, Gromnica-Ihle E, Krar e A, Natusch Mrasound of proximal upper extremity arteries to increa the diagnosticyield in largevessel giant cell arteritis. Rheumatology. 20

14. Arida A, Kyprianou M, Kanakis M, Sf. PP. M. J stic value of ultrasonography-derived edema the poral artery wall in giant cell arteritis: a second meta-anal s. BMC Mus ckelet Disord. 2010;11. https://
doi.org/10.1186/1471-247 1 -

15. Laria A, Lurati A, Scarpellini M. C duplex ultrasonography findings of temporal arteries in of giant arteritis: role in diagnosis and follow-up. Open access heumatol. 2017:9:55-9.

16. Klink T, Geiger, Heinzelmann S, Reinhard M, Holl-Ulrich K, Duwendag D, Vaith Vey TA. Giant cell arteritis: diagnostic accuracy of MR imaging f superficial Mlal arteries in initial diagnosis-results from a multicen - Dadiology. 2014;273:844-52.

17. Fitzgerald M, Savilly oR, Lewis R. Decision curve analysis. JAMA. 2015;13:409-10.

18. Seeliger B, S. najd J, Robson JC, Judge A, Craven A, Grayson PC, Suppiah RS, Watts

RA, Merkel P, Luqmani RA. Are the 1990 American College of Rheumatology ulitis classification criteria still valid? Rheumatology. 2017;56:1154-61.

TA, Reinhard M, Hauenstein C, Markl M, Warnatz K, Hetzel A, Uhl M, h P, Langer M. Comparison of duplex sonography and high-resolution agnetic resonance imaging in the diagnosis of giant cell (temporal) arteritis. Arthritis Rheum. 2008;58:2574-8.

. Patil P, Achilleos K, Williams M, Maw W, Dejaco C, Borg F, Gupta S, Dasgupta B. Outcomes and cost-effectiveness analysis of fast track pathway in giant cell arteritis. Rheumatology. 2014;53:15-6.

21. Patil P, Williams M, Maw WW, Achilleos K, Elsideeg S, Dejaco C, Borg F, Gupta S, Dasgupta B. Fast track pathway reduces sight loss in giant cell arteritis: results of a longitudinal observational cohort study. Clin Exp Rheumatol. 2015;33:S-103-6.

22. Laskou F, Coath Fiona C, Aung T, Benerjee S, Dasgupta B. Fast track giant cell arteritis clinic and pathway for early management of suspected giant cell arteritis: an audit. Rheumatology. 2018;57. https://doi.org/10.1093/ rheumatology/key075.298.

23. Schmidt WA. Ultrasound in the diagnosis and management of giant cell arteritis. Rheumatology. 2018;57:ii22-31.

24. Abdul-Rahman AM, Molteno AC, Bevin TH. The epidemiology of giant cell arteritis in Otago, New Zealand: a 9-year analysis. N Z Med J. 2011;124:44-52.

25. Bas-Lando M, Breuer GS, Berkun Y, Mates M, Sonnenblick M, Nesher G. The incidence of giant cell arteritis in Jerusalem over a 25-year period: annual and seasonal fluctuations. Clin Exp Rheumatol. 2007;25:S15-7.

26. McLachlan RHP, Lennox AF, Varcoe RL, Thomas SD. Endovascular treatment of critical lower limb ischemia caused by giant cell arteritis. J Vasc Surg Cases Innov Tech. 2019;5:31-4.

27. Bley TA, Geiger J, Jacobsen S, Wieben O, Markl M, Vaith P, Grist T, Langer M, Uhl M. High-resolution MRI for assessment of middle meningeal artery involvement in giant cell arteritis. Ann Rheum Dis. 2009;68:1369-70.

\section{Publisher's Note}

Springer Nature remains neutral with regard to jurisdictional claims in published maps and institutional affiliations. 